\title{
The mechanism of ATP-dependent RNA unwinding by DEAD box proteins
}

\author{
Manuel Hilbert, Anne R. Karow and Dagmar \\ Klostermeier*
}

Biozentrum, Biophysical Chemistry, University of Basel, Klingelbergstrasse 70, CH-4056 Basel, Switzerland

${ }^{*}$ Corresponding author

e-mail: dagmar.klostermeier@unibas.ch

\begin{abstract}
DEAD box proteins catalyze the ATP-dependent unwinding of double-stranded RNA (dsRNA). In addition, they facilitate protein displacement and remodeling of RNA or RNA/protein complexes. Their hallmark feature is local destabilization of RNA duplexes. Here, we summarize current data on the DEAD box protein mechanism and present a model for RNA unwinding that integrates recent data on the effect of ATP analogs and mutations on DEAD box protein activity. DEAD box proteins share a conserved helicase core with two flexibly linked RecAlike domains that contain all helicase signature motifs. Variable flanking regions contribute to substrate binding and modulate activity. In the presence of ATP and RNA, the helicase core adopts a compact, closed conformation with extensive interdomain contacts and high affinity for RNA. In the closed conformation, the RecA-like domains form a catalytic site for ATP hydrolysis and a continuous RNA binding site. A kink in the backbone of the bound RNA locally destabilizes the duplex. Rearrangement of this initial complex generates a hydrolysisand unwinding-competent state. From this complex, the first RNA strand can dissociate. After ATP hydrolysis and phosphate release, the DEAD box protein returns to a low-affinity state for RNA. Dissociation of the second RNA strand and reopening of the cleft in the helicase core allow for further catalytic cycles.
\end{abstract}

Keywords: ATP hydrolysis; conformational changes; coupling; helicase; protein dynamics; RNA duplex destabilization.

\section{Introduction}

Helicases unwind double-stranded nucleic acids in an ATP-dependent manner (Pyle, 2008). DNA helicases unwind double-stranded DNA regions and are involved in DNA replication, recombination and repair and overall genome stability (Singleton et al., 2007). RNA helicases, in contrast, remodel RNA or RNA/protein complex structures in all processes that involve RNA (Cordin et al., 2006). According to the occurrence of conserved sequence motifs, helicases are grouped into up to five superfamilies (Gorbalenya and Koonin, 1993). RNA helicases are part of the helicase superfamily 2 (SF2), which comprises the DExD/H proteins, the RecQ family, and members of the SWI/SNF family. DExD/H proteins are further divided into the DEAD, DEAH, and DExH family, according to the sequence in the corresponding signature motif. DExD/H proteins share a common domain organization but differ with respect to function and mechanism. In this review, we will focus on DEAD box proteins, which constitute the largest subfamily of SF2 helicases. Members of this family share a $\sim 400$ amino acid core region comprising highly conserved helicase signature motifs (Figure 1). Among them is the name giving DEAD box, a conserved motif with the amino acid sequence DEAD. The frequently used designation 'DEAD box helicases' refers to the ability of many but not all members of the DEAD box family to unwind RNA duplexes at the expense of ATP hydrolysis. Although for some time RNA unwinding has been believed to be the hallmark reaction catalyzed by all DEAD box proteins, unwinding activity was only demonstrated for some representatives, and in fact other DEAD box proteins have been implicated in a variety of functions such as remodeling structures of RNA or RNA/protein complexes (Cheng et al., 2005; Linder, 2006), dissociating RNA/protein complexes (Fairman et al., 2004) or RNA annealing (Yang and Jankowsky, 2005; Halls et al., 2007; Rajkowitsch et al., 2007). In these processes, they facilitate the (local) disruption of secondary and tertiary structure and of RNA-protein interactions. As such they are involved in all facets of RNA metabolism, from transcription, mRNA splicing and translation, RNA modification, and transport, ribosome biogenesis and RNA/protein complex assembly in general, to RNA degradation (Cordin et al., 2006).

DEAD box proteins share a common architecture. Their 'helicase core' consists of two independent RecA-like domains, connected by a short, flexible linker (Figures 1 and 2). In all DEAD box protein structures determined to date, the conserved helicase motifs are distributed in a similar three-dimensional arrangement on the RecA-like domains. The $\mathrm{N}$-terminal RecA-like domain provides the structural scaffold for the motifs I-III, and the C-terminal RecA-like domain harbors motifs IV, V, and VI. Mutations in these helicase motifs affect nucleotide binding, ATP hydrolysis, RNA binding, or unwinding. A few mutations have been reported that uncouple ATP hydrolysis from RNA binding and unwinding without affecting binding of ATP or RNA (Pause and Sonenberg, 1992; Cheng et al., 2005; Sengoku et al., 2006; Karow and Klostermeier, 2009). From extensive mutational studies on several 


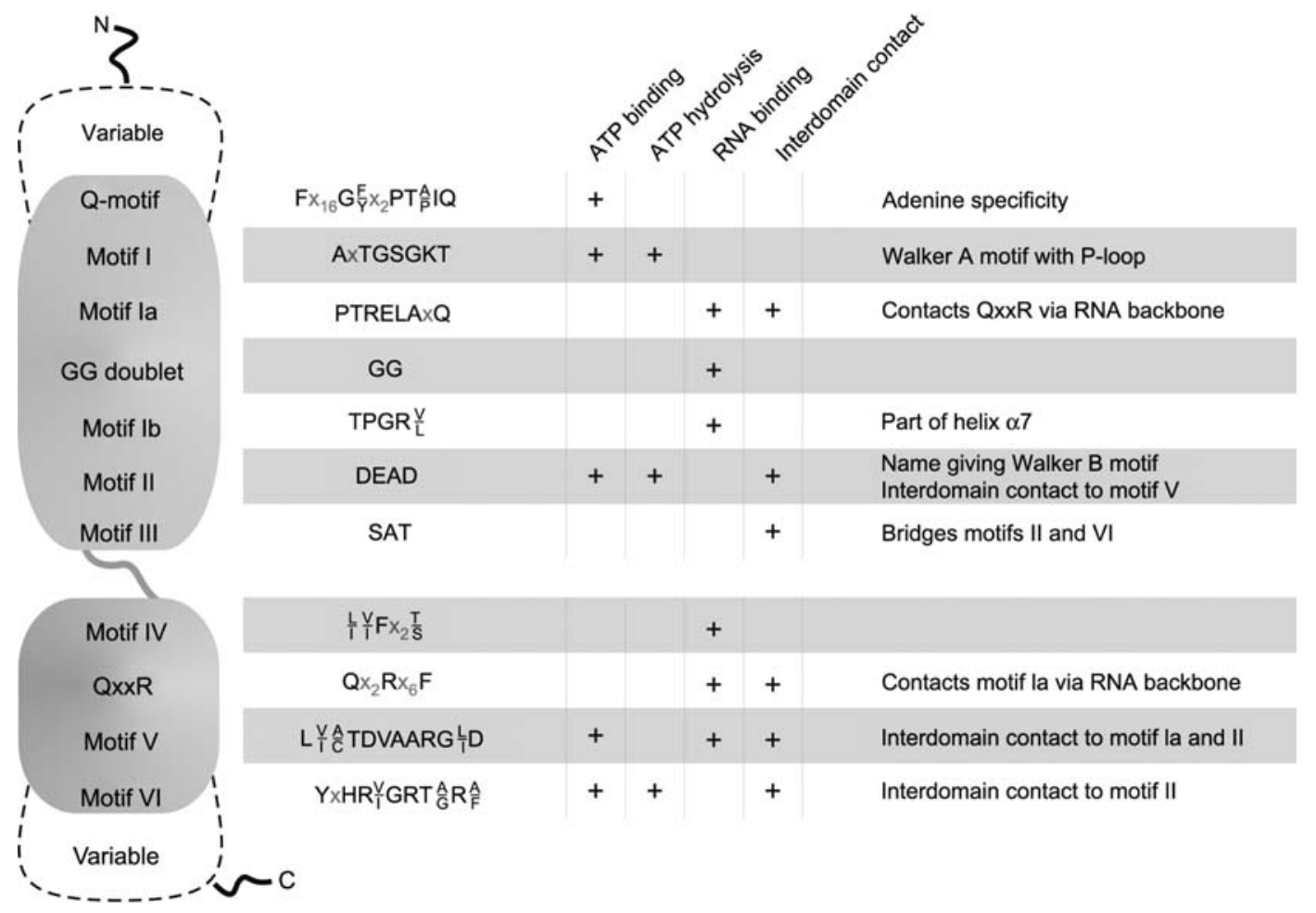

Figure 1 Conserved motifs in the DEAD box helicase core and their contributions to nucleotide binding and hydrolysis, RNA binding, and interdomain contacts.

DEAD box proteins share a conserved core that consists of two RecA-like domains (gray) and can be flanked by variable N-and Cterminal extensions. The helicase core contains all helicase signature motifs. Consensus sequences are derived from an alignment of 920 DEAD box proteins from reviewed sequences in the UniProt database (UniProt-Consortium, 2008), using the presence of a DEAD box plus a Q-motif as a selection criterion. A single amino acid is given in the consensus if this amino acid was found in $>65 \%$ of the sequences. The two most abundant amino acids are given if their combined occurrence is $>70 \%$. Positions with less conservation are marked with $\mathrm{x}$.

\section{A}

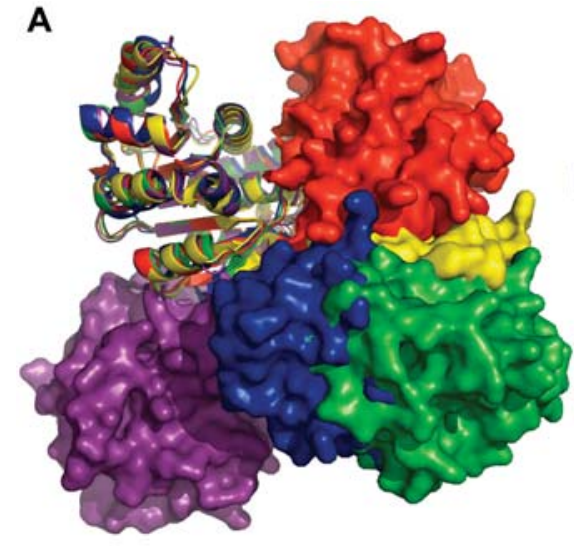

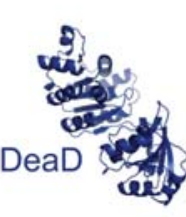

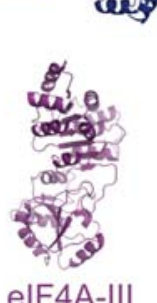

mjDEAD
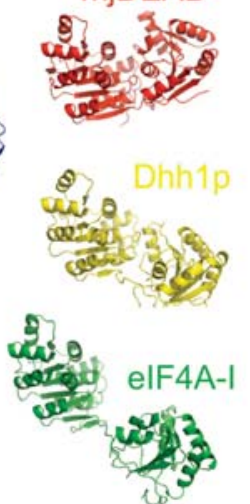

B

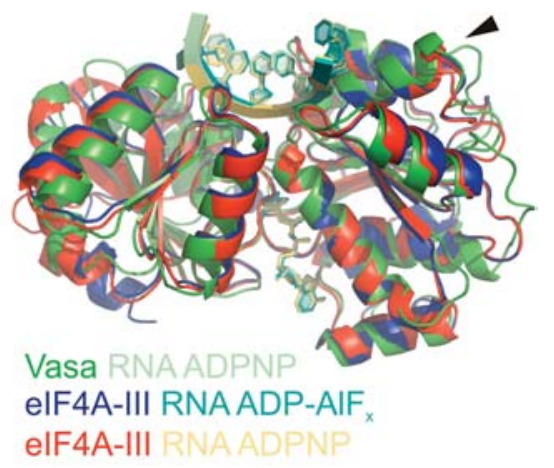

Figure 2 Open and closed conformations of DEAD box proteins.

(A) Different conformations of the DEAD box helicase core in the absence of ligands. The crystal structures of mjDeaD (Methanococcus jannaschii, red, PDB-ID 1hv8), Dhh1p (Saccharomyces cerevisiae, yellow, PDB-ID 1s2m), elF4A-I (S. cerevisiae, green, PDB-ID 1fuu), DeaD (Sulfolobus tokodaii, blue, PDB-ID 2z0m), and elF4A-III (human, purple, PDB-ID 2hxy) were superimposed on the N-terminal RecA-like domain, and the C-terminal domain is shown in surface representation. (B) Similar conformations of the helicase core of elF4A-III and Vasa in the presence of ssRNA and ADPNP or ADP-AIF . The structure of Vasa (Drosophila melanogaster, PDB-ID 2db3, green) in complex with RNA and ADPNP (light green) is superimposed with elF4A-III (human) in complex with ADPNP and RNA (blue/ cyan) or RNA and ADP-AIF (red/yellow). The overall structures of these three complexes are highly similar, including the positions and conformations of bound nucleotide and RNA. The triangle marks helix $\alpha 7$ that causes a kink in the bound RNA (see close-up in panel B).

DEAD box proteins, a consensus on the individual functions of the conserved helicase motifs has been obtained (Figure 1). In general, motifs I and II are implicated in
ATP binding and hydrolysis, with contributions from motif VI. Motif III is believed to couple ATP hydrolysis to RNA unwinding. Motifs IV, V, and VI contribute to RNA 
binding. Details on the specific function of conserved motifs will be discussed in the following sections.

Notably, mutations in conserved motifs can have different effects in different DEAD box proteins, indicating that the specific structural context influences the significance of a motif. Structural studies have provided a first glimpse on the individual interactions between the conserved motifs in the absence or presence of ATP and ssRNA substrate (Caruthers et al., 2000; Story et al., 2001; Cheng et al., 2005; Andersen et al., 2006; Bono et al., 2006; Sengoku et al., 2006; Nielsen et al., 2008; Collins et al., 2009; von Moeller et al., 2009). When both substrates are bound, the helicase motifs engage in a complex network with a multitude of cooperative interactions, complicating the assignment of functional contributions for each individual motif in mutagenesis studies (Banroques et al., 2008). The complete interaction network and its role for DEAD box protein activity are thus not yet fully understood.

In the absence of nucleotide or RNA substrate, the two RecA-like domains in the helicase core do not interact. Crystal structures of various DEAD box proteins without ligands show a large variety of relative orientations of the two RecA-like domains (Figure 2A; Caruthers et al., 2000; Story et al., 2001; Cheng et al., 2005; Andersen et al., 2006) and point to a significant flexibility that is presumably provided by the linker region. Solution studies of the Bacillus subtilis DEAD box protein YxiN are in agreement with such a high flexibility. Small angle X-ray scattering (Wang et al., 2007) and single molecule FRET experiments (Theissen et al., 2008) show an extended conformation in solution, consistent with an open conformation of the helicase core. No nucleotide binding is observed when the two RecA-like domains are mixed without a covalent linkage (Karow et al., 2007), confirming that interactions between these domains are weak. In contrast to the open conformation in the absence of ligands, the helicase core of DEAD box proteins adopts a compact, closed conformation in the presence of ssRNA and nucleotide, as exemplified by the crystal structures of the DEAD box proteins elF4A-III, Vasa, and Ddx19 in complex with ssRNA and the non-hydrolyzable ATP-analog ADPNP (Andersen et al., 2006; Bono et al., 2006; Sengoku et al., 2006; Collins et al., 2009; von Moeller et al., 2009; Figure 2B). In these structures, most of the conserved motifs face the interdomain cleft between the RecA-like domains and are engaged in a complex hydrogen bond network. The nucleotide is buried at the bottom of the interdomain cleft and interacts with residues from both domains. Similarly, the ssRNA contacts both RecA-like domains and stabilizes the closed conformation. The transition from the flexible open conformation to the more rigid closed conformation is only observed when both ATP and RNA are present (Theissen et al., 2008; Karow and Klostermeier, 2009). Thus, it appears to be an important checkpoint in the catalytic cycle of DEAD box proteins. The similar architecture of the closed conformations between DEAD box proteins from different organisms points to a common mechanism for the helicase core. In contrast to the similar arrangement of the two domains, the connecting linker region adopts different conformations in the closed structures of elF4AIII, Vasa, and Ddx19. Stepwise conversion of the elF4A linker to the corresponding Vasa sequence resulted in enhanced ATPase activity, revealing the linker as a regulatory element (Low et al., 2007).

In all crystal structures, the phosphate backbone of the bound ssRNA shows a sharp bend in the same position that prevents canonic A-form RNA geometry. It was postulated that the formation of the closed conformer is coupled to this distortion of the RNA and thereby facilitates double-strand destabilization (Andersen et al., 2006; Bono et al., 2006; Sengoku et al., 2006). However, further experimental evidence for the distortion is lacking and the kink is observed in complex with ADPNP and ADP-AIF ${ }_{x}$, nucleotides that do not allow for unwinding.

The helicase core on its own is an RNA-stimulated ATPase and has the ability to unwind short RNA duplexes (Rogers et al., 1999). Its affinities for RNA are regulated by the nucleotide state and it thus functions as a nucleotide-dependent molecular switch (Lorsch and Herschlag 1998a,b). However, only few examples of DEAD box proteins consist of an isolated helicase core, among them the translation initiation factor elF4A, or the Methanococcus jannaschii DeaD protein. In numerous DEAD box proteins, the helicase core provides the basic DEAD box protein functions, and large $\mathrm{N}$ - and/or C-terminal extensions (Figure 1) modulate the activity of the helicase core by conferring substrate specificity or by mediating contacts with interacting proteins (Schmid and Linder 1992; see 'Modulation of the helicase core activity by interacting partners and flanking domains'). In addition, the helicase core appears as a module in several enzymes involved in nucleic acid processing, such as DNA topoisomerases (Confalonieri et al., 1993; Rodriguez and Stock, 2002), restriction enzymes (Gorbalenya and Koonin, 1991; Szczelkun, 2000), chromatin remodeling enzymes (Flaus and Owen-Hughes, 2001), or Dicer (Ma et al., 2008).

This year marks the 20th anniversary of the 'Birth of the DEAD box' (Linder et al., 1989). Despite a wealth of information gained during two decades, the catalytic mechanism of DEAD box proteins is not yet fully understood. Open questions include: What is the role of the conformational change in the helicase core for strand displacement? What is the conformation of the RNA substrate bound to the helicase core? How is ATP hydrolysis coupled to RNA unwinding, and at which stage does ATP hydrolysis occur? Which step of the nucleotide cycle triggers RNA release? What are the functions of additional domains and interacting proteins? In this review, we summarize the current knowledge on mechanistic aspects of DEAD box protein activity.

\section{Interaction of DEAD box proteins with adenine nucleotides and RNA}

The interactions of DEAD box protein with adenine nucleotide and RNA substrates have been characterized using a variety of equilibrium and non-equilibrium methods. Nucleotide and RNA binding have been widely studied in crosslinking and filter binding experiments (Pause and Sonenberg, 1992; Pause et al., 1993; Lorsch and Hers- 
chlag, 1998a; Tanner et al., 2003; Sengoku et al., 2006). These experiments are not performed under equilibrium conditions, but nevertheless they have been very valuable for comparing relative affinities of one DEAD box protein for different nucleotides, or for comparing nucleotide or RNA affinities of different DEAD box protein mutants. Nucleotide binding constants have also been derived from 'equilibrium filtration' experiments (Polach and Uhlenbeck, 2002), and RNA binding constants have been determined in electrophoretic mobility shift assays (Pause et al., 1993; Henn et al., 2001; Polach and Uhlenbeck, 2002; Cordin et al., 2004; Karginov et al., 2005; Talavera et al., 2006; Banroques et al., 2008; Liu et al., 2008). In these experiments, the equilibrium is only minimally perturbed. Equilibrium dissociation constants can be obtained directly in fluorescence titrations of fluorescently labeled nucleotides or RNA. Nucleotide binding can be investigated via fluorescence of mant nucleotides (Henn et al., 2002, 2008; Talavera and De La Cruz, 2005; Karow et al., 2007; Theissen et al., 2008; Karow and Klostermeier, 2009), and RNA binding can be monitored via fluorescence anisotropy using fluorescently labeled RNAs (Karow et al., 2007; Marintchev et al., 2009). Fluorescence spectroscopy has also been employed to directly determine rate constants for nucleotide binding and dissociation (Henn et al., 2002, 2008) and for RNA unwinding (Karow et al., 2007). The fact that DEAD box proteins are RNA-stimulated ATPases provides a further means to characterize their interactions with RNA and ATP (Lorsch and Herschlag, 1998a,b; Tsu and Uhlenbeck, 1998; Kossen and Uhlenbeck, 1999; Tsu et al., 2001; Polach and Uhlenbeck, 2002; Karow et al., 2007; Henn et al., 2008; Theissen et al., 2008; Karow and Klostermeier, 2009). Michaelis-Menten constants for ATP in the absence and presence of RNA substrates can provide a measure for the corresponding dissociation constants. Likewise, a 'Michaelis-Menten' constant for RNA in the presence of ATP can be determined that represents an apparent dissociation constant of DEAD box protein/ RNA complexes and, although not a genuine dissociation constant, allows for rapid comparison of RNA binding to different mutants and different DEAD box proteins. The interpretation of steady-state ATPase data is complicated by the fact that the nucleotide state under the experimental conditions depends on the nature of the rate-limiting step in the nucleotide cycle. Although all cited methods provide valuable insights on enzyme-substrate interaction, results obtained by different methods have to be compared with care, and in some cases comparison might be difficult or even impossible.

In contrast to the moderate RNA affinity of the DEAD box helicase core, flanking domains can bind RNA with high affinities. When overall RNA affinities are determined, nucleotide-dependent substrate binding properties of the core will thus be masked by the nucleotideindependent high RNA affinity of the flanking domain, and it is crucial to dissect the individual contributions. Recent evidence suggests that additional domains can also influence nucleotide binding (Collins et al., 2009; Fan et al., 2009; Napetschnig et al., 2009; von Moeller et al., 2009), see also the section on 'modulation of the helicase core activity by interacting partners and flanking domains'.
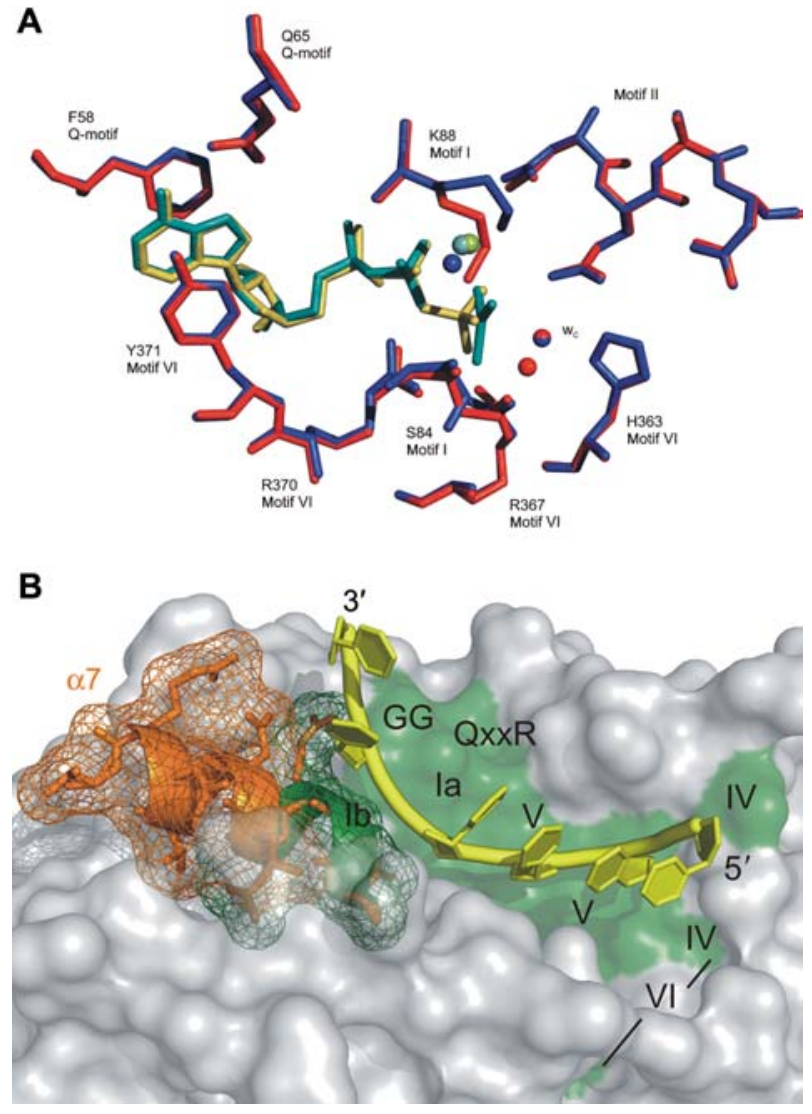

Figure 3 Nucleotide and RNA binding.

(A) Nucleotide binding pocket. Superposition of the structures of elF4A-III in complex with ADPNP and ssRNA (red, nucleotide/ $\mathrm{Mg}^{2+}$ in yellow), and in complex with ADP-AIF ${ }_{x}$ and ssRNA (blue, nucleotide/ $\mathrm{Mg}^{2+}$ in cyan). Water molecules that contact the nucleotide in these structures are depicted as red and blue sphere, respectively. The side chain conformations of amino acids contributing to nucleotide binding and hydrolysis are similar in both structures, with the exception of S84 and K88 (motif l). The catalytic water molecule ( $w_{c}$, red/blue sphere) is in nearly the same location in both structures. The side chain of D342 (motif $\mathrm{VI}$ ) contacts the 2'-OH but has been omitted for clarity. (B) RNA binding site: the ssRNA (yellow) bound to Vasa (gray surface) is kinked. The RNA distortion is not compatible with regular A-RNA conformation and can thus destabilize RNA duplexes bound to DEAD box helicases. Steric hindrance owing to the position of helix $\alpha 7$ (orange) causes the kink after nucleotide U5. Conserved motifs involved in RNA binding are highlighted in green.

\section{Nucleotide binding}

The nucleotide binding pocket in DEAD box proteins is formed by a Walker A motif (motif I), a Walker B motif (DEAD box, motif II), and the Q-motif (Figure 3A). The Walker A motif contains the characteristic P-loop (Saraste et al., 1990; Leipe et al., 2003) with a conserved lysine that contacts the $\beta$ - and $\gamma$-phosphates. Residues from motifs I and II contact the triphosphate part of the nucleotide directly and through water and $\mathrm{Mg}^{2+}$ (Andersen et al., 2006; Bono et al., 2006; Sengoku et al., 2006; von Moeller et al., 2009). In addition, motif VI from the C-terminal RecA-like domain interacts with the triphosphate in the closed conformation (Bono et al., 2006; Sengoku et al., 2006; von Moeller et al., 2009). Whereas motifs I and II are present in various other ATPases (Wal- 
ker et al., 1982), the Q-motif upstream of motif I is unique to DEAD box proteins (Tanner, 2003; Tanner et al., 2003). Its highly conserved glutamine interacts with the adenine base and provides specificity for adenine nucleotides. Other nucleotides might compete for the binding site but are not efficiently hydrolyzed and do not stimulate RNA unwinding by DEAD box proteins (Du et al., 2002; Franca et al., 2007; Garcia and Uhlenbeck, 2008). It has therefore been suggested that the Q-motif also contributes to positioning of the nucleotide for hydrolysis (Tanner, 2003; Tanner et al., 2003). The phenylalanine of the Q-motif stacks with the adenine base that is also contacted by an aromatic or hydrophobic side chain from motif $\mathrm{Vl}$ (Bono et al., 2006). Only the $3^{\prime}-\mathrm{OH}$ group of the ribose is contacted, rationalizing the weak discrimination between ATP and dATP (Du et al., 2002). In addition to direct and indirect contacts to the nucleotides, the conserved motifs from both RecA-like domains form an intricate interaction network around the ATPase site. In some cases, the isolated N-terminal RecA-domain interacts (weakly) with nucleotides (Rudolph et al., 2006; Fan et al., 2009; Napetschnig et al., 2009), whereas no interaction with nucleotides was detected for the YxiN N-terminal RecAlike domain (Karow et al., 2007). The interaction of the nucleotide with both domains provides the link to its influence on RNA binding and remodeling.

Early experiments to understand the nucleotide cycle of DEAD box proteins addressed binding of ADP and ATP. DEAD box proteins bind ADP one order of magnitude more tightly than ATP (Lorsch and Herschlag, 1998a; Talavera and De La Cruz, 2005; Karow et al., 2007). The higher affinity for ADP compared to ATP explains the observed product inhibition of the ATPase activity (Lorsch and Herschlag, 1998a). In addition, the lack of contributions of the $\gamma$-phosphate to nucleotide affinity is an indication for ATP-driven conformational changes. Limited proteolysis experiments provide further evidence for ATP-induced conformational changes (Lorsch and Herschlag, 1998b; Henn et al., 2002; Cheng et al., 2005; Low et al., 2007).

Tremendous insight into the mechanism of DEAD box protein activity has been gained from studies using ATP analogs such as ATP $y S$, ADPNP, ADP-BeF ${ }_{x}$, and ADP$A F_{x}$. The role of nucleotides for RNA unwinding will be discussed in the section 'the mechanism of DEAD box helicases: ATP hydrolysis and its coupling to RNA unwinding' below.

\section{RNA binding}

DEAD box proteins functionally interact with RNA via the helicase core. Flanking domains can contribute high affinity and/or high specificity RNA binding. For example, the C-terminal domains of the splicing helicases CYT-19 and Mss116 mediates interactions with structured RNA (Grohman et al., 2007; Mohr et al., 2008). In contrast, the C-terminal domains of DbpA and YxiN specifically interact with a hairpin in ribosomal RNA (Diges and Uhlenbeck, 2001; Tsu et al., 2001; Kossen et al., 2002; Karginov et al., 2005; Wang et al., 2006), and the C-terminal domain of Hera provides high affinity for ribosomal RNA and RNase P RNA, among others (Morlang et al., 1999; Linden et al., 2008). The influence of domains flanking the helicase core on RNA binding and on DEAD box mechanism in general will be discussed in detail in 'Modulation of the helicase core activity by interacting partners and flanking domains'. Here we focus on the RNA binding properties of the core domain.

The translation initiation factor elF4A consists of the helicase core without any additional domains and thus represents a minimal DEAD box protein. As a consequence, the RNA binding properties of elF4A reflect RNA binding to the isolated helicase core. elF4A possesses a moderate RNA affinity without sequence specificity (Rogers et al., 1999, 2002). The $K_{d}$ values for singlestranded RNA are in the low micromolar range, and no or weak binding of dsRNA has been detected (Lorsch and Herschlag, 1998a). In agreement with common properties of the helicase core, the truncation of flanking domains in DEAD box helicases reduces their RNA affinity to the level observed for elF4A (Karginov et al., 2005; Grohman et al., 2007; Mohr et al., 2008).

The RNA binding site of the helicase core is formed by both RecA-like domains, and binding involves contacts to motifs la, GG, and Ib in the N-terminal domain, and to motifs IV, QxxR, V, and VI in the C-terminal domain (Pause et al., 1993; Andersen et al., 2006; Bono et al., 2006; Sengoku et al., 2006; Nielsen et al., 2008; Collins et al., 2009; von Moeller et al., 2009) (Figures 1 and 3B). In all available structures, the $\mathrm{N}$-terminal RecA-like domain binds the $3^{\prime}$-region of the SsRNA substrate, and the C-terminal domain binds the 5'-region. The continuous bipartite RNA binding site is stabilized by a network of interdomain interactions. Motifs la from the $\mathrm{N}$-terminal and motif QxxR from the C-terminal RecA-like domain contact the same phosphate and might therefore contribute to the stabilization of the closed conformation (Bono et al., 2006; Sengoku et al., 2006). Whereas the ribose phosphate backbone of the RNA is extensively contacted, no interactions occur with the nucleobases of the RNA, explaining the lack of sequence specificity. Direct contacts to $2^{\prime}-\mathrm{OH}$ groups of the ribose moieties lead to a discrimination against DNA as a substrate (Peck and Herschlag, 1999; Rogers et al., 2001a; Bono et al., 2006; Sengoku et al., 2006). RNA binding to the open conformation in the absence of ATP only occurs with very low affinity as the bipartite binding site is not aligned.

Most nucleotides of the ssRNA bound to the closed helicase core are stacked, but stacking is interrupted between nucleotides 5 and 6 (numbering according to the Vasa structure; Sengoku et al., 2006). This leads to the striking feature of a kink in the phosphate-ribose backbone between these nucleotides (Figure 3B). This kink has consistently been observed in all structures of closed DEAD box helicase cores known to date and is caused by a steric hindrance with helix $\alpha 7$ (Figure 3B) that counteracts a straight binding of RNA. As this kink is not compatible with canonical A-form geometry and thus with dsRNA, it has been proposed to constitute a first step towards RNA unwinding (Sengoku et al., 2006). Helix $\alpha 7$ equivalents in other SF2 families adopt different conformations that would not impose a kink on the bound RNA. Hence, the RNA distortion might be a special feature of DEAD box proteins and point towards a unique mechanism of unwinding. 
Although all crystals of DEAD box proteins with RNA have been obtained with longer single-stranded oligo-uridine, only six or seven nucleotides of the RNA substrate are visible in the electron densities. However, no structural data on relevant physiological unwinding substrates of DEAD box proteins are available, limiting possible functional conclusions. First efforts to define the size of the RNA binding site investigated the interaction of elF4A with RNA substrates of different lengths and revealed that ssRNAs of 11-18 nucleotides interact with elF4A and stimulate its intrinsic ATPase activity (Abramson et al., 1987; Goss et al., 1987). A 20mer was used to describe the minimal kinetic and thermodynamic framework of the nucleotide cycle in the presence of RNA for elF4A and demonstrated coupling between nucleotide state and RNA affinity (Lorsch and Herschlag, 1998a). Since then, functional interaction with unstructured RNAs of $\sim 15$ nucleotides was shown for several DEAD box helicases (Peck and Herschlag, 1999; Bizebard et al., 2004; Garcia and Uhlenbeck, 2008). RNA protection experiments showed that $\sim 10$ nucleotides are protected by binding to elF4A (Le Hir et al., 2000; Ballut et al., 2005; Rozovsky et al., 2008). However, already 2-4 RNA nucleotides within a DNA molecule lead to a stimulation of ATPase activity (Peck and Herschlag, 1999). The necessity of much larger RNA fragments to fully stimulate ATPase activity of some DEAD box proteins most likely is not an intrinsic core characteristic but can be ascribed to interaction of a structured substrate with additional domains (Garcia and Uhlenbeck, 2008). Interacting proteins might also increase the size of the RNA binding site. The RNA binding site of elF4A increases from $\sim 17$ to $\sim 30$ nucleotides in the presence of its interacting partners elF4H or elF4B (Rozovsky et al., 2008), and to $>60$ bp in the elF4F complex (Kaye et al., 2009). Altogether, it appears that binding already occurs with rather short RNA molecules, but full activation of the DEAD box protein might require larger nucleic acids interacting with the core.

\section{Cooperativity of RNA and nucleotide binding}

In principle, binding of two different ligands can occur in a random or ordered manner. The binding sites can be independent, or coupled to each other via positive or negative cooperativity. Early experiments suggested sequential binding of ATP and RNA (Abramson et al., 1987; Pause et al., 1993). This conclusion resulted from the low RNA affinity of the helicase core in the absence of nucleotides, making RNA binding difficult to detect. For elF4A, cooperative binding of ssRNA and ATP was demonstrated, but no evidence of sequential binding was observed (Lorsch and Herschlag, 1998a,b). Cooperative binding of RNA and ATP has been demonstrated for various other DEAD box proteins (Mohr et al., 2002; Polach and Uhlenbeck, 2002; Cordin et al., 2004; Elles and Uhlenbeck, 2008; Theissen et al., 2008) and has been established as a general feature, although kinetic data do not support this cooperativity for DbpA (Henn et al., 2008). In the other case where no apparent cooperativity has been observed (Grohman et al., 2007; Mohr et al., 2008), C-terminal domains contribute the largest part of the RNA affinity and mask nucleotide-dependent RNA binding properties of the core. elF4A appears to bind ADP and ssRNA with negative cooperativity (Lorsch and Herschlag, 1998a), whereas other DEAD box proteins investigated show little or no cooperativity in binding of ADP and single-stranded or structured RNA (Cordin et al., 2004; Henn et al., 2008; Nielsen et al., 2008; Theissen et al., 2008). A detailed analysis of the nucleotide cycle of DbpA revealed the post-hydrolysis ADP- $P_{i}$ state rather than the initial ATP complex or the ADP state as a high-affinity state with regard to RNA (Henn et al., 2008). These results imply that phosphate release resets the helicase from the ADP- $P_{1}$ state with high affinity for RNA to the ADP state with low RNA affinity. Consistent with this notion, duplex unwinding in the presence of $\mathrm{ADP}-\mathrm{BeF}_{\mathrm{x}}$, but not ADP-AIF , was demonstrated (Liu et al., 2008), suggesting that unwinding occurs before ATP hydrolysis and hydrolysis is required for resetting the enzyme for further catalytic cycles (see the following section).

The flexible connection of the two helicase domains renders it likely that rearrangements of the domains occur during the catalytic cycle. Indirect evidence for such a conformational reorganization is available from different proteolysis patterns in the presence or absence of substrates (Lorsch and Herschlag, 1998b; Henn et al., 2002; Cheng et al., 2005; Low et al., 2007). Nucleotide binding kinetics support nucleotide-driven conformational rearrangements: ATP and ADP binding follows a single exponential in the absence of RNA, but a second slow phase appears when RNA is present. The slow step might reflect a (local or global) conformational reorganization (Henn et al., 2008). The domain reorientation upon cooperative binding of ADPNP and RNA binding has been demonstrated directly in single molecule FRET experiments (Theissen et al., 2008), and the first structure of the closed DEAD box protein core (Sengoku et al., 2006) has rationalized the observed communication between nucleotide and RNA binding sites. Ddx19 and elF4A-III are the only DEAD box proteins for which structures have been determined both in open and closed conformations (Andersen et al., 2006; Collins et al., 2009; von Moeller et al., 2009). In the closed conformation, ATP and RNA interact with both RecA-like domains of the core. Thus, both ATP and RNA binding stabilize the closed conformation, explaining the observed cooperativity.

\section{The mechanism of DEAD box helicases: ATP hydrolysis and its coupling to RNA unwinding}

\section{Characteristics of RNA helicase substrates}

The unwinding mechanism of DEAD box proteins is principally different from DNA helicases. Highly processive DNA helicases are motor proteins that translocate with a defined directionality along DNA stretches and unwind thousands of base pairs without dissociation from their DNA substrates (Singleton et al., 2007). Remodeling of RNA structures by DEAD box proteins does not require unwinding of long stretches of dsRNA, and DEAD box proteins achieve duplex separation through local base 
pair disruption. The closely related DExH RNA helicases, however, exhibit intermediate processivity (Jankowsky et al., 2000). Many of these enzymes are viral proteins and might require processivity for functions during viral replication.

DEAD box proteins bind tightly to single-stranded RNA (ssRNA) but do not or only weakly interact with dsRNA (Lorsch and Herschlag, 1998a). The presence of singlestranded regions facilitates loading of DEAD box protein onto their RNA substrate (Yang and Jankowsky, 2006; Halls et al., 2007). Interestingly, a continuous backbone of the ssRNA and the unwinding target is not required, but a close proximity is sufficient (Yang and Jankowsky, 2006). In addition, unwinding does not necessarily start at the end of a duplex but can also be facilitated internally and therefore does not depend on single-strand/ double-strand junctions (Yang and Jankowsky, 2006; Halls et al., 2007). As an alternative to ssRNA loading, many DEAD box proteins are brought into proximity of their unwinding target by ancillary domains that mediate RNA binding and tether the DEAD box helicase core on large RNA substrates (see section on 'modulation of the helicase core activity by interacting partners and flanking domains'). As a consequence, duplex disruption or RNA/ RNP remodeling by DEAD box proteins is an inherently local activity. Although different unwinding activities of DEAD box proteins for duplexes with 5 '- or 3 '-single stranded overhangs have been reported, this 'directionality' possibly reflects differences in unwinding that depend on the relative orientation of the DEAD box protein with regard to the target region. For example, the Cterminal domain of DbpA recognizes a hairpin in ribosomal 23S rRNA and the helicase core unwinds an adjacent helix (Fuller-Pace et al., 1993; Diges and Uhlenbeck, 2001; Tsu et al., 2001). Unwinding efficiencies depend on the position of the helix relative to the hairpin (Diges and Uhlenbeck, 2005). If the hairpin is located on the $3^{\prime}$-side of the helical region, the helix is efficiently unwound. When the hairpin is moved to the 5 '-side, no duplex unwinding is observed. However, an increased linker length between the hairpin on the $5^{\prime}$-side and the helix restores unwinding efficiency, suggesting that the flexibility of the longer linker allows for proper positioning of the helix to be unwound for the helicase core (Diges and Uhlenbeck, 2005).

\section{Mechanism of ATP hydrolysis}

The catalytic site for ATP hydrolysis of DEAD box proteins is assembled at the interface of the two RecA-like domains in the helicase core by closure of the interdomain cleft in response to RNA and ATP binding. The mechanism of ATP hydrolysis by DEAD box proteins has become evident from mutagenesis studies and from structures of the closed helicase core in complex with ADPNP and ssRNA (Andersen et al., 2006; Bono et al., 2006; Sengoku et al., 2006; Collins et al., 2009; von Moeller et al., 2009), and with the transition state analog ADP-AIF $_{x}$ and ssRNA (Nielsen et al., 2008; Figure 3A). Mutations in motifs I and II (Walker A and B motifs) render DEAD box proteins ATPase-deficient. A conserved lysine in motif I, the glutamate in motif II, and an arginine in motif VI are essential for catalysis (Rozen et al., 1989;
Elles and Uhlenbeck, 2008). The motif I lysine bridges the $\beta$ - and $\gamma$-phosphates and presumably coordinates the $\gamma$-phosphate while it is transferred from the $\beta$-phosphate to the catalytic water (Bono et al., 2006; Nielsen et al., 2008; Figure 3A). A water molecule embedded in interactions with side chains from motifs II, V, and VI close to the $\gamma$-phosphate is in appropriate geometry for nucleophilic attack on the scissile bond (Andersen et al., 2006; Sengoku et al., 2006). Similar to mutations in motifs I and II, mutation of a conserved arginine in motif $\mathrm{VI}$ abolishes the ATPase activity (Elles and Uhlenbeck, 2008). This arginine contacts the $\gamma$-phosphate and might stabilize the transition state (Sengoku et al., 2006; Elles and Uhlenbeck, 2008; Nielsen et al., 2008). Its role would be reminiscent of the arginine finger in GTPase activating proteins (Ahmadian et al., 1997). The structure of elF4A-

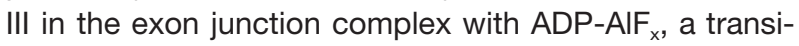
tion state analog, is indicative of a dissociative mechanism for phosphoryl transfer (Nielsen et al., 2008). elF4A-III adopts the closed conformation in complex with $A D P-A I F_{x}$. Interestingly, the overall structure is nearly identical to the ADPNP state of other DEAD box proteins, with small differences limited to the immediate environment of the $\gamma$-phosphate (Nielsen et al., 2008; Figure 3A).

\section{Coupling of ATP hydrolysis and duplex separation}

Strand separation is a thermodynamically unfavorable reaction. DEAD box protein mediated duplex unwinding requires ATP, and it has been inferred that the energy from ATP hydrolysis is required for base pair disruption. By contrast, many DEAD box proteins already promote limited strand separation in the absence of ATP, which has been interpreted as nonspecific duplex destabilization via an ssRNA capture mechanism (Del Campo et al., 2007; Chen et al., 2008). For a few DEAD box proteins, a strand annealing activity has been demonstrated (Yang and Jankowsky, 2005; Halls et al., 2007). In contrast to unwinding, strand annealing is an ATP-independent process (Halls et al., 2007) and is even inhibited by ATP (Yang and Jankowsky, 2005).

Unraveling the molecular mechanism that leads to coupling of ATP hydrolysis and duplex unwinding requires a thorough dissection of individual steps in the nucleotide cycle and assessment of their effects on RNA binding and unwinding. The nucleotide cycle regulates the transition of DEAD box proteins through different nucleotide states with different RNA affinities. The ADP and nucleotide-free states exhibit low RNA affinity (Lorsch and Herschlag, 1998a; Henn et al., 2008; Nielsen et al., 2008). In contrast, the ADP- $P_{i}$ state exhibits high RNA affinity (Henn et al., 2008). Non-hydrolyzable ATP analogs, such as ADPNP, ADP-BeF $x$, and ADP-AIF , promote high affinity RNA binding (Ballut et al., 2005; Liu et al., 2008; Nielsen et al., 2008; Rozovsky et al., 2008; Theissen et al., 2008), but different results have been obtained for ATP itself: high RNA affinity was reported for the ATP state of DbpA (Polach and Uhlenbeck, 2002; Elles and Uhlenbeck, 2008), whereas the ATP states of Dbp5 and elF4A exhibit low RNA affinity (Nielsen et al., 2008; Rozovsky et al., 2008).

The potential of ATP analogs (or lack thereof) to support unwinding supports the notion that ATP hydrolysis 
is required for base-pair disruption. ADPNP is not hydrolyzed by DEAD box proteins and does not support RNA unwinding (Liu et al., 2008; Theissen et al., 2008). In contrast, ATP $\gamma S$, which is frequently used as a 'nonhydrolyzable' nucleotide analog for many ATPases, is efficiently hydrolyzed by elF4A and supports RNA unwinding (Peck and Herschlag, 2003). Although ATP $\gamma S$ is hydrolyzed 10-fold more slowly than ATP, the unwinding rates with ATP- and ATP $\gamma S$ are similar, suggesting that the chemical step of ATP hydrolysis is not rate limiting for RNA unwinding (Peck and Herschlag, 2003). Dissection of individual steps in the nucleotide cycle of DbpA has provided a kinetic and thermodynamic framework for the nucleotide cycle and its links to RNA binding and unwinding (Henn et al., 2008). Phosphate release was identified as a rate-limiting step both in the absence and in the presence of RNA (Henn et al., 2008), in line with similar rates of ATP- and ATP $\gamma$ S-supported RNA unwinding (Peck and Herschlag, 2003). Recently, the effect of the ATP analogs ADP-BeF ${ }_{x}$ and ADP-AIF on RNA unwinding has been examined (Liu et al., 2008). ADP-BeF $F_{x}$ is a ground state ATP analog, whereas ADP$\mathrm{AlF}_{\mathrm{x}}$ mimics the transition state. The structure of elF4AIII in complex with ADP-AIF ${ }_{x}$ confirms that it acts as a transition state analog for DEAD box proteins (Nielsen et al., 2008). ADP-BeF ${ }_{x}$ and $A D P-A F_{x}$ favor high-affinity ssRNA binding (Liu et al., 2008) similar to ADPNP. Interestingly, ADP-BeF ${ }_{x}$ facilitates RNA unwinding by Ded1p under single turnover conditions. In contrast, ADP-AIF and $A D P-P_{i}$ do not support RNA unwinding, suggesting that strand separation occurs prior to ATP hydrolysis (Liu et al., 2008). Duplex unwinding can be achieved by hydrolysis of one ATP molecule, and under certain conditions less than one ATP is hydrolyzed per duplex separation event (Chen et al., 2008). In fact, ATP bound to the helicase core was only hydrolyzed in half of the strand separation events (Chen et al., 2008), further supporting that strand separation can precede hydrolysis. Strikingly, ADP-BeF ${ }_{x}$ does not support unwinding by the DExH box protein NPH-II (Liu et al., 2008). Thus, the mechanism of coupling the nucleotide cycle to duplex unwinding appears to be specific for DEAD box proteins.

Under multiple turnover conditions, where unwinding is efficient in the presence of ATP, ADP-BeF ${ }_{x}$ is not sufficient to promote RNA unwinding. Consequently, ATP hydrolysis must be required to reset the enzyme and to enable multiple turnovers (Liu et al., 2008). ADP-BeF appears to faithfully mimic the ATP conformation of DEAD box proteins, whereas it has been suggested that ADPNP traps a non-productive DEAD box protein/RNA complex (Henn et al., 2008) and does not elicit the same conformation of DEAD box proteins as ATP (Chen et al., 2008; Liu et al., 2008). Although ADPNP does not support RNA unwinding, its binding to the helicase core allows for the closure of the interdomain cleft in response to RNA binding (Andersen et al., 2006; Bono et al., 2006; Theissen et al., 2008; Karow and Klostermeier, 2009; von Moeller et al., 2009). The closed conformation of YxiN in complex with ADPNP resembles the closed conformation with ATP (Theissen et al., 2008; Karow and Klostermeier, 2009), suggesting that global conformations are similar, and the difference between the ATP and ADPNP confor- mations must be subtle. Consistent with this notion, the global structure of elF4A-III/ADP-AIF ${ }_{x}$ with ssRNA bound is virtually identical to the ADPNP complex, with small local differences around the $\gamma$-phosphate (Nielsen et al., 2008; Figure 3A). The structures of Mss116 in complex with ssRNA and ADPNP, ADP-BeF ${ }_{x}$ and $A D P-A F_{x}$ were recently determined (Del Campo and Lambowitz, 2009). All three structures do not reveal any significant differences outside the ATP binding site, suggesting that there is no apparent structural reason for different capacities to support unwinding.

\section{A unifying mechanism for DEAD box protein activity?}

The observation that duplex separation might precede ATP hydrolysis is not unexpected. The kink in the backbone of ssRNA bound to the closed conformation of the helicase core interferes with base pairing (Figure 3B). The introduction of this kink would thereby lead to the separation of the first few base pairs of the RNA substrate, and it has been interpreted as a possible first step towards unwinding (Sengoku et al., 2006; Karow and Klostermeier, 2009). The low affinity of DEAD box proteins for ATP compared to ADP might not only reflect the energetic cost for ATP-induced conformational changes of the protein but also for distortion of the RNA. Kinking the substrate is a consequence of the closure of the interdomain cleft in the helicase core but does not require ATP hydrolysis (Karow and Klostermeier, 2009). Consequently, all nucleotides that favor the closed conformation of the helicase core should lead to a kink in the RNA substrate. If the remaining double helical region is unstable, disruption of these few base pairs would already result in dissociation of the first RNA strand and in unwinding (Rogers et al., 1999). However, ADPNP and ADP-AIF allow for the distortion of the ssRNA and yet do not support RNA unwinding. In this respect, it is interesting to note that a rearrangement of the elF4A/ATP complex towards a hydrolysis-competent conformation was proposed earlier (Peck and Herschlag, 1999). The recent observation of two phases for nucleotide binding in the presence of structured RNA also supports the notion of two ATP complexes (Henn et al., 2008). These data can be integrated in a model in which initial binding of ATP and dsRNA to DEAD box proteins is followed by a rearrangement to a hydrolysis- and unwindingcompetent complex (Figure 4). The different capacities of ATP analogs to support unwinding suggest that this rearrangement can also take place in the presence of ADP-BeF ${ }_{x}$. In contrast, the ADPNP and ADP-AIF ${ }_{x}$ complexes do not undergo this activation, and thus ADPNP and $A D P-A F_{x}$ cannot support RNA unwinding. From the activated complex, the first strand of the bound RNA can dissociate, resulting in RNA unwinding. Liu and colleagues have speculated that the flexibility of the singlestranded RNA product is required for local conformational adjustments that lead to ATP hydrolysis (Liu et al., 2008). In this scenario, ATP hydrolysis would be a consequence of (and subsequent to) unwinding rather than the cause, and the two processes would be tightly linked. If the first RNA strand dissociates from the helicase before ATP hydrolysis, as suggested by Liu and cowork- 
ers, unwinding has already been favored by ATP binding and RNA distortion (Figure 4), rationalizing RNA unwinding without ATP hydrolysis (Chen et al., 2008). Kinetic partitioning between RNA dissociation and ATP hydrolysis could explain the influence of duplex length on ATP consumption (Figure 4): whereas one round of ATP hydrolysis leads to a large fraction of, or even complete, unwinding for short helices, more ATP is required for unwinding of longer helices (Rogers et al., 1999; Chen et al., 2008). The probability of a kink and unwinding of a few base pairs to cause complete strand separation is high for short duplexes, whereas for longer helices one round of nucleotide-regulated conformational changes results in a lower probability of strand separation. Thus, for longer duplexes, ATP is hydrolyzed while both RNA strands are still bound, generating the ADP- $P_{i}$ state (Figure 4). Possibly, the increased flexibility of the complex owing to the local distortion of the RNA is sufficient to allow for ATP hydrolysis.

It is currently unclear which step in the nucleotide cycle triggers release of the second RNA strand. Its dissociation should be linked to the reopening of the interdomain cleft in the helicase core. The ADP- $P_{i}$ state is difficult to populate and has not been accessible in single molecule FRET experiments (Theissen et al., 2008). However, this state shows tight coupling with RNA binding (Henn et al., 2008), suggesting that it must be in the closed conformation. By contrast, the helicase core is mainly in the open conformation in the presence of ADP and RNA (Theissen et al., 2008), suggesting that phosphate release from the ADP- $P_{i}$ state should trigger reopening of the interdomain cleft. Consistent with these observations, kinetic evidence suggests that phosphate release might be linked to RNA release (Henn et al., 2008). Both findings are consistent with the reduced SsRNA affinity of DEAD box proteins in complex with ADP (Lorsch and Herschlag, 1998a; lost et al., 1999; Cordin et al., 2004).

In the current scenario of the DEAD box protein mechanism, RNA unwinding is initiated and is sometimes even completed by distorting the bound RNA in the ATPbound state. This state can be mimicked by ADP-BeF but not by ADPNP. ATP hydrolysis is required to reset the enzyme to a low-affinity state for RNA and to allow for multiple rounds of unwinding (Chen et al., 2008). For DEAD box proteins with additional RNA binding domains, the helicase core might remain tethered to the RNA substrate, allowing for multiple catalytic cycles (Diges and Uhlenbeck, 2001; Tijerina et al., 2006). Remodeling of RNP complexes can be rationalized by the same mechanism and would be a consequence of local distortions of the RNA that interfere with protein binding.

\section{Modulation of the helicase core activity by interacting partners and flanking domains}

The helicase core provides all basic properties required for a functional DEAD box protein. Nevertheless, the properties of the helicase core are modulated in virtually all DEAD box proteins. Regulation can be either in cis or in trans. For example, few DEAD box proteins contain insertions into the conserved core scaffold. Many DEAD box proteins contain additional flanking domains that affect the helicase core in cis. The prototypic DEAD box protein elF4A that consists only of a helicase core is part of a large interaction network and is extensively regulated by interaction partners in trans.

\section{Modulation by insertions and flanking domains}

The human Ded1p homolog Ddx3x/y helicase core contains a unique 10 aa insertion between the P-loop and motif la. This insertion folds into a helix and forms a continuous positive patch together with a loop enriched

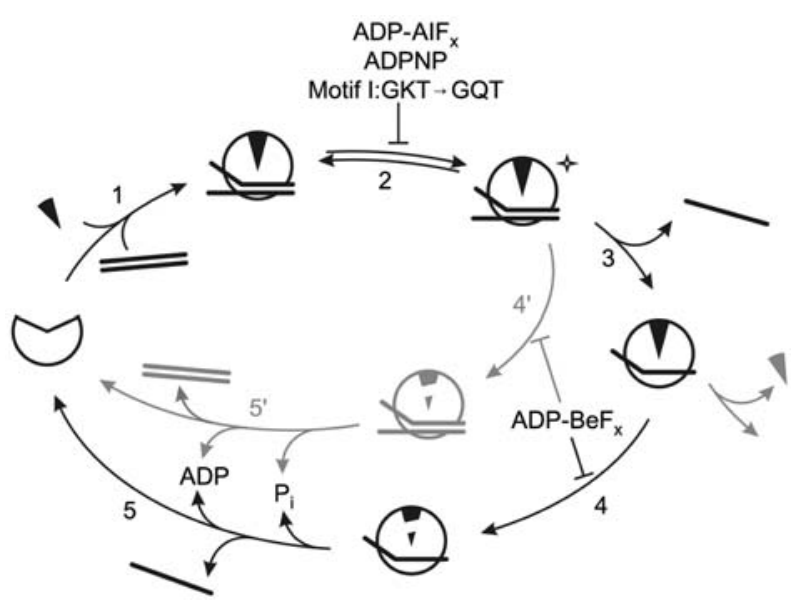

Figure 4 Possible catalytic cycle of RNA unwinding by DEAD box proteins.

DEAD box proteins bind dsRNA (line pair) and ATP (black triangle, step 1). In complex with ATP and RNA, the DEAD box protein adopts a closed conformation. One strand of the bound RNA is kinked, leading to the local destabilization of (terminal or internal) base pairs. The initial complex undergoes a rearrangement towards an activated, hydrolysis- and unwinding-competent conformation (star, step 2; Peck and Herschlag, 1999; Henn et al., 2008). The structural difference between these two complexes is currently unclear. From the activated complex, the first RNA strand can dissociate (step 3 ) before ATP is hydrolyzed (step 4). Product release is coupled to the dissociation of the second RNA strand (step 5), thereby resetting the enzyme for further cycles. Possibly, ATP can dissociate before being hydrolyzed (gray, right arm), allowing for the completion of one cycle of unwinding in the absence of ATP hydrolysis (Chen et al., 2008). For longer RNA duplexes, destabilization by the kink does not lead to the same probability for complete strand separation, and dissociation of the first RNA strand from the activated complex. Possibly, the increased flexibility of the complex owing to transient local unwinding of the RNA allows for ATP hydrolysis to occur. In this case, ATP is hydrolyzed before the first RNA strand dissociates (step 4'). Product release and dissociation of the RNA (step $5^{\prime}$ ) reset the enzyme for further cycles. The partitioning between dissociation of the first strand and ATP hydrolysis rationalizes the higher amount of ATP required for unwinding longer duplexes (Rogers et al., 1999; Chen et al., 2008). The nucleotide analogs ADPNP and ADP-AIF ${ }_{x}$ do not promote the rearrangement towards the activated (hydrolysis- and unwinding-competent) complex (step 2) and thus do not support RNA unwinding. The unwinding deficiency of motif I mutants can be rationalized similarly. In the presence of $A D P-B F_{x}$, the activation takes place and RNA unwinding becomes possible. However, in the absence of hydrolysis, the enzyme is not released from the second RNA strand and cannot undergo multiple catalytic cycles. 
in positively charged side chains that is also unique to $\mathrm{Ddx} 3 \mathrm{x} / \mathrm{y}$. As this patch is localized close to the expected position of the $3^{\prime}$-end of bound RNA, it has been suggested that the insertion increases the RNA binding surface and contributes to RNA binding (Hogbom et al., 2007). A striking example for a SF2-like module with an insertion is the helicase-like domain in reverse gyrase which provides the nucleotide-dependent DNA binding to this topoisomerase (Del Toro Duany et al., 2008). Here, a small domain of $\sim 75$ aa that is homologous to the transcription termination factor Rho, the so-called latch domain, is inserted into the C-terminal RecA-like domain (Rodriguez and Stock, 2002). The latch domain interacts with the topoisomerase domain and has been implicated in communication between the two domains during positive DNA supercoiling by reverse gyrase (Rodriguez, 2002, 2003).

The helicase core of Dbp5/Ddx19 is flanked by an Nterminal extension that appears to contribute to nucleotide binding (Collins et al., 2009; Fan et al., 2009; Napetschnig et al., 2009; von Moeller et al., 2009). A homologous region is also found in Ddx25. In Ddx19, the $\alpha$-helix $\mathrm{N}$-terminal to the helicase core is inserted in the cleft of the helicase core in the presence of ADP (Collins et al., 2009). When ADPNP and ssRNA are bound, the Ddx19 core adopts the closed conformation, and the $\mathrm{N}$-terminal helix is packed onto the surface of the C-terminal RecA-like domain, whereas it interacts with the N-terminal RecA-like domain in the structure of Ddx19 with its interaction partner Nup214 (Napetschnig et al., 2009). Deletion experiments point towards a regulatory role of the Ddx19 N-terminal extension on Ddx19 activity (Collins et al., 2009).

In various DEAD box proteins, domains flanking the helicase core mediate interactions with RNA substrates or possibly also with other proteins. RNA binding domains can provide high affinity, high specificity, or both. The DEAD box proteins DbpA (Escherichia coli) and its $B$. subtilis homolog YxiN bind to hairpin 92 in the ribosomal 23S rRNA with high affinity and specificity and have been implicated in ribosome biogenesis (FullerPace et al., 1993; Nicol and Fuller-Pace, 1995; Kossen and Uhlenbeck, 1999; Kossen et al., 2002). The crystal structure of the C-terminal RNA-binding domain (RBD) of YxiN adopts a classical RNA-recognition motif (RRM) fold (Wang et al., 2006). However, aromatic residues on the face of the $\beta$-sheet are not required for RNA binding, suggesting an unusual RNA binding mode. Instead, conserved lysines in two loops might be involved in RNA binding. The isolated RBD binds hairpin 92 with similar affinity as the full-length YxiN protein (Karginov et al., 2005; Wang et al., 2007). YxiN unwinds a short double helix adjacent to hairpin 92, and it has been suggested that the RBD functions as an anchor to direct the unwinding activity of the helicase core to this region. However, localization of the RBD with respect to the helicase core in the structure is currently unknown.

A similar RRM-fold domain, the so-called GUCT domain, is present in Ddx21 and Ddx50 (RNA helicase II-Gu isoforms $\alpha$ and $\beta$, respectively) (Ohnishi et al., 2008). Its negative surface potential, however, is not consistent with RNA binding and might point towards a different function.
The DEAD box protein Hera from Thermus thermophilus contains a flanking region C-terminal to the helicase core. As a unique feature so far, this C-terminal domain is bipartite and consists of a dimerization motif (Klostermeier and Rudolph, 2009; Rudolph et al., 2009), and an RBD that mediates high affinity interaction with ribosomal RNA fragments and RNase P RNA (Linden et al., 2008). Despite the lack of sequence similarity with YxiN, the Hera RBD folds into a modified RRM (Rudolph and Klostermeier, 2009). Hera is the first example where the orientation of the RNA binding domain with respect to the helicase core has been determined (Klostermeier and Rudolph, 2009; Rudolph et al., 2009; Rudolph and Klostermeier, 2009).

Some DEAD box proteins contain basic C-terminal extensions rich in arginines, serines and glycines. Examples are the splicing helicases Cyt-19 and Mss116 (Mohr et al., 2002; Huang et al., 2005; Halls et al., 2007) that are general RNA chaperones, and Ded1p, a helicase involved in translation (lost et al., 1999). These proteins bind unspecifically to structured RNA via their basic Cterminal extensions, and their helicase cores then unwind loosely attached neighboring double helical regions (Grohman et al., 2007; Mohr et al., 2008). In Cyt-19 and Mss116, a $\alpha$-helical region is located between the helicase core and the basic tail. A high RNA-stimulated ATPase activity is maintained when the basic tail is deleted, but mutations in the $\alpha$-helical region strongly inhibit RNA-dependent ATPase activity, pointing to different functions of these two regions in modulating activity of the helicase core (Mohr et al., 2008). A recently reported structure of Mss116 that includes the $\alpha$-helical region reveals a second kink in the bound RNA caused by the presence of the $\alpha$-helical region (Del Campo and Lambowitz, 2009), indicating that these extensions might also contribute to RNA unwinding.

The substrate specificity of DEAD box proteins can be transferred by fusing the RNA binding domain to a different helicase core (Kossen et al., 2002). Similarly, the RNA specificity of the C-terminal domains can be exploited to direct a DEAD box protein to a specific unwinding substrate (Chen et al., 2008). These findings underscore the modular character of DEAD box proteins. In general, tethering of DEAD box proteins to their RNA substrate by high-affinity RNA binding of their C-terminal domains is not compatible with a translocation mechanism of processive helicases and local action is a unique feature of DEAD box helicases.

\section{Regulation by other protein factors}

Nucleotide-regulated transitions between open and closed conformations of the helicase core are at the heart of DEAD box protein activity. Stabilization of either of these conformations or affecting the kinetics of their interconversion constitutes an attractive and efficient way for the regulation of DEAD box protein activity. A prominent example for such a regulation mechanism is elF4A. Its intrinsically very weak helicase activity is stimulated by various other translation factors (Rogers et al., 2001a; Korneeva et al., 2005; Oberer et al., 2005; Schutz et al., 2008; Marintchev et al., 2009). A well-studied example is the functional interaction of elF4A with elF4G. elF4G 
contacts both RecA-like domains of elF4A with a conserved HEAT sequence (Oberer et al., 2005; Bellsolell et al., 2006; Schutz et al., 2008). As a consequence of this bipartite interaction, the two RecA-like domains in the elF4A helicase core are fixed in a partly open conformation (Caruthers et al., 2000; Schutz et al., 2008). As the interaction with elF4G stimulates the elF4A ATPase and helicase activities, transitions of elF4A between open and closed conformations have to be possible in the complex. Binding of elF4G to the C-terminal RecA domain of elF4A covers a large surface area and involves numerous interactions, whereas few contacts are formed with the N-terminal RecA domain (Schutz et al., 2008). The presence of two interaction sites, a primary, highaffinity site combined with a secondary low-affinity interaction site, could allow for the required flexibility of the elF4AVelF4G complex. It can be envisaged that the lowaffinity interface transiently opens during the catalytic cycles of elF4A, consistent with a previously proposed 'soft-clamp' mechanism (Oberer et al., 2005). Regulation of elF4A activity by other translation factors might follow a similar regulation principle. For elF4B and elF4H, stable interactions with the $\mathrm{N}$-terminal domain of elF4A in the presence of ADPNP and ssRNA have been demonstrated, and there is evidence for additional interactions with the C-terminal domains (Rozovsky et al., 2008).

Based on a similar regulation principle, inhibition of DEAD box proteins can be achieved by interaction partners that stabilize a single conformation and interfere with shuttling between open and closed conformations. One example is the isoform III of elF4A which is part of the exon junction complex. In the exon junction complex structure, elF4A-III bound to ADPNP and ssRNA adopts a closed conformation (Andersen et al., 2006; Bono et al., 2006). Both domains of elF4A are contacted by MLN51 (Brz). The bipartite interaction of MLN51 with elF4A is stabilized by the other components of the complex, MAGO and Y-14 (Andersen et al., 2006; Bono et al., 2006). Although ATP hydrolysis is still possible, ATP turnover is inhibited by preventing product dissociation (Nielsen et al., 2008). As a consequence, elF4A is trapped in the ADP- $P_{i}$ form, tightly bound to its RNA substrate, consistent with stable RNA binding as its main function (Nielsen et al., 2008).

A similar model might be more common as a regulatory principle for helicase domains that are part of larger functional units where the helicase domain is just one among many other functional domains, such as reverse gyrase or Dicer. The variety of modulation principles indicates a large repertoire of mechanisms in the modulation of DEAD box protein activities and of tailoring the helicase core properties to a specific DEAD box protein function.

\section{Conclusions}

The DEAD box protein core is a nucleotide-dependent switch that adopts an open conformation in the absence of ligands and in the ADP state, and in a closed conformation in the ATP (and ADP- $\mathrm{P}_{\mathrm{i}}$ ) states. The closure of the interdomain cleft in the helicase core is coupled to high- affinity RNA binding and to a distortion of the bound RNA. This distortion is a critical feature of DEAD box protein activity. However, formation of a complex with a kinked RNA substrate does not necessarily lead to unwinding, suggesting that an activation step, a rearrangement of the initial complex to a hydrolysis- and unwinding-competent state, has to occur. Such an activation step can be inferred from biochemical data, but its nature is currently unknown. From this activated complex, one RNA strand can dissociate from the destabilized duplex and strand separation can precede ATP hydrolysis. Dissociation of the second RNA strand is most likely coupled to phosphate release. ATP hydrolysis is not required for strand separation but for release of the second RNA strand and for resetting the enzyme for multiple turnovers. The same model can also account for other activities of DEAD box proteins, such as protein displacement and structural remodeling. Variations of the common DEAD box protein scheme can be achieved by flanking domains that confer high RNA affinity or specificity, contribute to nucleotide binding, or mediate interactions with other proteins. Future experiments should address the existence and nature of the two ATP complexes, and the role of phosphate release for the mechanism of DEAD box proteins.

\section{Acknowledgments}

Work on the DEAD box protein mechanism in the authors' laboratory was funded by the Volkswagenstiftung (D.K.), the Swiss National Science Foundation (D.K.), the Verband der Chemischen Industrie (M.H.), the European Molecular Biology Organization (M.H.), and the Roche Research Foundation (M.H.).

\section{References}

Abramson, R.D., Dever, T.E., Lawson, T.G., Ray, B.K., Thach, R.E., and Merrick, W.C. (1987). The ATP-dependent interaction of eukaryotic initiation factors with mRNA. J. Biol. Chem. 262, 3826-3832.

Ahmadian, M.R., Stege, P., Scheffzek, K., and Wittinghofer, A. (1997). Confirmation of the arginine-finger hypothesis for the GAP-stimulated GTP-hydrolysis reaction of Ras. Nat. Struct. Biol. 4, 686-689.

Andersen, C.B., Ballut, L., Johansen, J.S., Chamieh, H., Nielsen, K.H., Oliveira, C.L., Pedersen, J.S., Seraphin, B., Le Hir, H., and Andersen, G.R. (2006). Structure of the exon junction core complex with a trapped DEAD-box ATPase bound to RNA. Science 313, 1968-1972.

Ballut, L., Marchadier, B., Baguet, A., Tomasetto, C., Seraphin, B., and Le Hir, H. (2005). The exon junction core complex is locked onto RNA by inhibition of elF4AIll ATPase activity. Nat. Struct. Mol. Biol. 12, 861-869.

Banroques, J., Cordin, O., Doere, M., Linder, P., and Tanner, N.K. (2008). A conserved phenylalanine of motif IV in superfamily 2 helicases is required for cooperative, ATP-dependent binding of RNA substrates in DEAD-box proteins. Mol. Cell. Biol. 28, 3359-3371.

Bellsolell, L., Cho-Park, P.F., Poulin, F., Sonenberg, N., and Burley, S.K. (2006). Two structurally atypical HEAT domains in the $\mathrm{C}$-terminal portion of human elF4G support binding to elF4A and Mnk1. Structure 14, 913-923. 
Bizebard, T., Ferlenghi, I., lost, I., and Dreyfus, M. (2004). Studies on three $E$. coli DEAD-box helicases point to an unwinding mechanism different from that of model DNA helicases. Biochemistry 43, 7857-7866.

Bono, F., Ebert, J., Lorentzen, E., and Conti, E. (2006). The crystal structure of the exon junction complex reveals how it maintains a stable grip on mRNA. Cell 126, 713-725.

Caruthers, J.M., Johnson, E.R., and McKay, D.B. (2000). Crystal structure of yeast initiation factor $4 A$, a DEAD-box RNA helicase. Proc. Natl. Acad. Sci. USA 97, 13080-13085.

Chen, Y., Potratz, J.P., Tijerina, P., Del Campo, M., Lambowitz, A.M., and Russell, R. (2008). DEAD-box proteins can completely separate an RNA duplex using a single ATP. Proc. Natl. Acad. Sci. USA 105, 20203-20208.

Cheng, Z., Coller, J., Parker, R., and Song, H. (2005). Crystal structure and functional analysis of DEAD-box protein Dhh1p. RNA 11, 1258-1270.

Collins, R., Karlberg, T., Lehtio, L., Schutz, P., van den Berg, S., Dahlgren, L.G., Hammarstrom, M., Weigelt, J., and Schuler, H. (2009). The DExD/H-box RNA helicase DDX19 is regulated by an a-helical switch. J. Biol. Chem. 284, 10296-10300.

Confalonieri, F., Elie, C., Nadal, M., de La Tour, C., Forterre, P., and Duguet, M. (1993). Reverse gyrase: a helicase-like domain and a type I topoisomerase in the same polypeptide. Proc. Natl. Acad. Sci. USA 90, 4753-4757.

Cordin, O., Tanner, N.K., Doere, M., Linder, P., and Banroques, J. (2004). The newly discovered $Q$ motif of DEAD-box RNA helicases regulates RNA-binding and helicase activity. EMBO J. 23, 2478-2487.

Cordin, O., Banroques, J., Tanner, N.K., and Linder, P. (2006). The DEAD-box protein family of RNA helicases. Gene 367 , $17-37$.

Del Campo, M. and Lambowitz, A.M. (2009). Structure of the yeast DEAD-box protein Mss116p reveals two wedges that crimp RNA. Mol. Cell 35, 598-609.

Del Campo, M., Tijerina, P., Bhaskaran, H., Mohr, S., Yang, Q., Jankowsky, E., Russell, R., and Lambowitz, A.M. (2007). Do DEAD-box proteins promote group II Intron splicing without unwinding RNA? Mol. Cell 28, 159-166.

Del Toro Duany, Y., Jungblut, S.P., Schmidt, A.S., and Klostermeier, D. (2008). The reverse gyrase helicase-like domain is a nucleotide-dependent switch that is attenuated by the topoisomerase domain. Nucleic Acids Res. 36, 5882-5895.

Diges, C.M. and Uhlenbeck, O.C. (2001). Escherichia coli DbpA is an RNA helicase that requires hairpin 92 of $23 \mathrm{~S}$ rRNA. EMBO J. 20, 5503-5512.

Diges, C.M. and Uhlenbeck, O.C. (2005). Escherichia coli DbpA is a $3^{\prime} \rightarrow 5^{\prime}$ RNA helicase. Biochemistry $44,7903-7911$.

Du, M.X., Johnson, R.B., Sun, X.L., Staschke, K.A., Colacino, J., and Wang, Q.M. (2002). Comparative characterization of two DEAD-box RNA helicases in superfamily II: human translation-initiation factor $4 \mathrm{~A}$ and hepatitis $\mathrm{C}$ virus non-structural protein 3 (NS3) helicase. Biochem. J. 363, 147-155.

Elles, L.M. and Uhlenbeck, O.C. (2008). Mutation of the arginine finger in the active site of Escherichia coli DbpA abolishes ATPase and helicase activity and confers a dominant slow growth phenotype. Nucleic Acids Res. 36, 41-50.

Fairman, M.E., Maroney, P.A., Wang, W., Bowers, H.A., Gollnick, P., Nilsen, T.W., and Jankowsky, E. (2004). Protein displacement by DExH/D RNA helicases without duplex unwinding. Science 304, 730-734.

Fan, J.S., Cheng, Z., Zhang, J., Noble, C., Zhou, Z., Song, H., and Yang, D. (2009). Solution and crystal structures of mRNA exporter Dbp5p and its interaction with nucleotides. J. Mol. Biol. 388, 1-10.

Flaus, A. and Owen-Hughes, T. (2001). Mechanisms for ATPdependent chromatin remodelling. Curr. Opin. Genet. Dev. $11,148-154$

Franca, R., Belfiore, A., Spadari, S., and Maga, G. (2007). Human DEAD-box ATPase DDX3 shows a relaxed nucleoside substrate specificity. Proteins $67,1128-1137$.
Fuller-Pace, F.V., Nicol, S.M., Reid, A.D., and Lane, D.P. (1993). DbpA: a DEAD box protein specifically activated by $23 \mathrm{~s}$ rRNA. EMBO J. 12, 3619-3626.

Garcia, I. and Uhlenbeck, O.C. (2008). Differential RNA-dependent ATPase activities of four rRNA processing yeast DEADbox proteins. Biochemistry 47, 12562-12573.

Gorbalenya, A.E. and Koonin, E.V. (1991). Endonuclease (R) subunits of type-I and type-III restriction-modification enzymes contain a helicase-like domain. FEBS Lett. 291, 277-281.

Gorbalenya, A.E. and Koonin, E.V. (1993). Helicases: amino acid sequence comparisons and structure-function relationships. Curr. Opin. Struct. Biol. 3, 419-429.

Goss, D.J., Woodley, C.L., and Wahba, A.J. (1987). A fluorescence study of the binding of eucaryotic initiation factors to messenger RNA and messenger RNA analogues. Biochemistry 26, 1551-1556.

Grohman, J.K., Campo, M.D., Bhaskaran, H., Tijerina, P., Lambowitz, A.M., and Russell, R. (2007). Probing the mechanisms of DEAD-box proteins as general RNA chaperones: the C-terminal domain of CYT-19 mediates general recognition of RNA. Biochemistry 46, 3013-3022.

Halls, C., Mohr, S., Del Campo, M., Yang, Q., Jankowsky, E., and Lambowitz, A.M. (2007). Involvement of DEAD-box proteins in group I and group II intron splicing. Biochemical characterization of Mss116p, ATP hydrolysis-dependent and -independent mechanisms, and general RNA chaperone activity. J. Mol. Biol. 365, 835-855.

Henn, A., Medalia, O., Shi, S.P., Steinberg, M., Franceschi, F., and Sagi, I. (2001). Visualization of unwinding activity of duplex RNA by DbpA, a DEAD box helicase, at single-molecule resolution by atomic force microscopy. Proc. Natl. Acad. Sci. USA 98, 5007-5012.

Henn, A., Shi, S.P., Zarivach, R., Ben-Zeev, E., and Sagi, I. (2002). The RNA helicase DbpA exhibits a markedly different conformation in the ADP-bound state when compared with the ATP- or RNA-bound states. J. Biol. Chem. 277, 46559-46565.

Henn, A., Cao, W., Hackney, D.D., and De La Cruz, E.M. (2008). The ATPase cycle mechanism of the DEAD-box rRNA helicase, DbpA. J. Mol. Biol. 377, 193-205.

Hogbom, M., Collins, R., van den Berg, S., Jenvert, R.M., Karlberg, T., Kotenyova, T., Flores, A., Hedestam, G.B., and Schiavone, L.H. (2007). Crystal structure of conserved domains 1 and 2 of the human DEAD-box helicase DDX3X in complex with the mononucleotide AMP. J. Mol. Biol. 372, 150-159.

Huang, H.R., Rowe, C.E., Mohr, S., Jiang, Y., Lambowitz, A.M., and Perlman, P.S. (2005). The splicing of yeast mitochondrial group I and group II introns requires a DEAD-box protein with RNA chaperone function. Proc. Natl. Acad. Sci. USA 102, 163-168.

lost, I., Dreyfus, M., and Linder, P. (1999). Ded1p, a DEAD-box protein required for translation initiation in Saccharomyces cerevisiae, is an RNA helicase. J. Biol. Chem. 274, 1767717683.

Jankowsky, E., Gross, C.H., Shuman, S., and Pyle, A.M. (2000). The DExH protein NPH-II is a processive and directional motor for unwinding RNA. Nature 403, 447-451.

Karginov, F.V., Caruthers, J.M., Hu, Y., McKay, D.B., and Uhlenbeck, O.C. (2005). YxiN is a modular protein combining a $\mathrm{DEx}(\mathrm{D} / \mathrm{H})$ core and a specific RNA-binding domain. J. Biol. Chem. 280, 35499-35505.

Karow, A.R. and Klostermeier, D. (2009). A conformational change in the helicase core is necessary but not sufficient for RNA unwinding by the DEAD box helicase YxiN. Nucleic Acids Res. 37, 4464-4471.

Karow, A.R., Theissen, B., and Klostermeier, D. (2007). Authentic interdomain communication in an RNA helicase reconstituted by expressed protein ligation of two helicase domains. FEBS J. $274,463-473$ 
Kaye, N.M., Emmett, K.J., Merrick, W.C., and Jankowsky, E. (2009). Intrinsic RNA binding by the eukaryotic initiation factor $4 \mathrm{~F}$ depends on a minimal RNA length, but not on the $\mathrm{m} 7 \mathrm{G}$ cap. J. Biol. Chem. 284, 17742-17750.

Klostermeier, D. and Rudolph, M.G. (2009). A novel dimerization motif in the C-terminal domain of the Thermus thermophilus DEAD box helicase Hera confers substantial flexibility. Nucleic Acids Res. 37, 421-430.

Korneeva, N.L., First, E.A., Benoit, C.A., and Rhoads, R.E. (2005). Interaction between the $\mathrm{NH}_{2}$-terminal domain of elF4A and the central domain of elF4G modulates RNA-stimulated ATPase activity. J. Biol. Chem. 280, 1872-1881.

Kossen, K. and Uhlenbeck, O.C. (1999). Cloning and biochemical characterization of Bacillus subtilis YxiN, a DEAD protein specifically activated by 23 S rRNA: delineation of a novel sub-family of bacterial DEAD proteins. Nucleic Acids Res. 27, 3811-3820.

Kossen, K., Karginov, F.V., and Uhlenbeck, O.C. (2002). The carboxy-terminal domain of the DExDH protein YxiN is sufficient to confer specificity for $23 \mathrm{~S}$ rRNA. J. Mol. Biol. 324, 625636.

Le Hir, H., Izaurralde, E., Maquat, L.E., and Moore, M.J. (2000). The spliceosome deposits multiple proteins 20-24 nucleotides upstream of mRNA exon-exon junctions. EMBO J. 19, 6860-6869

Leipe, D.D., Koonin, E.V., and Aravind, L. (2003). Evolution and classification of P-loop kinases and related proteins. J. Mol. Biol. 333, 781-815.

Linden, M.H., Hartmann, R.K., and Klostermeier, D. (2008). The putative RNase $\mathrm{P}$ motif in the DEAD box helicase Hera is dispensable for efficient interaction with RNA and helicase activity. Nucleic Acids Res. 36, 5800-5811.

Linder, P. (2006). Dead-box proteins: a family affair - active and passive players in RNP-remodeling. Nucleic Acids Res. 34, 4168-4180.

Linder, P., Lasko, P.F., Ashburner, M., Leroy, P., Nielsen, P.J., Nishi, K., Schnier, J., and Slonimski, P.P. (1989). Birth of the D-E-A-D box. Nature 337, 121-122. [Erratum published in Nature 340 (1989), 246].

Liu, F., Putnam, A., and Jankowsky, E. (2008). ATP hydrolysis is required for DEAD-box protein recycling but not for duplex unwinding. Proc. Natl. Acad. Sci. USA 105, 20209-20214.

Lorsch, J.R. and Herschlag, D. (1998a). The DEAD box protein elF4A. 1. A minimal kinetic and thermodynamic framework reveals coupled binding of RNA and nucleotide. Biochemistry $37,2180-2193$

Lorsch, J.R. and Herschlag, D. (1998b). The DEAD box protein elF4A. 2. A cycle of nucleotide and RNA-dependent conformational changes. Biochemistry 37, 2194-2206.

Low, W.K., Dang, Y., Bhat, S., Romo, D., and Liu, J.O. (2007). Substrate-dependent targeting of eukaryotic translation initiation factor $4 \mathrm{~A}$ by pateamine $\mathrm{A}$ : negation of domain-linker regulation of activity. Chem. Biol. 14, 715-727.

Ma, E., MacRae, I.J., Kirsch, J.F., and Doudna, J.A. (2008). Autoinhibition of human dicer by its internal helicase domain. J. Mol. Biol. 380, 237-243.

Marintchev, A., Edmonds, K.A., Marintcheva, B., Hendrickson, E., Oberer, M., Suzuki, C., Herdy, B., Sonenberg, N., and Wagner, G. (2009). Topology and regulation of the human elF4A/4G/4H helicase complex in translation initiation. Cell 136, 447-460.

Mohr, S., Stryker, J.M., and Lambowitz, A.M. (2002). A DEADbox protein functions as an ATP-dependent RNA chaperone in group I intron splicing. Cell 109, 769-779.

Mohr, G., Del Campo, M., Mohr, S., Yang, Q., Jia, H., Jankowsky, E., and Lambowitz, A.M. (2008). Function of the C-terminal domain of the DEAD-box protein Mss116p analyzed in vivo and in vitro. J. Mol. Biol. 375, 1344-1364.

Morlang, S., Weglohner, W., and Franceschi, F. (1999). Hera from Thermus thermophilus: the first thermostable DEAD-box helicase with an RNase P protein motif. J. Mol. Biol. 294, 795-805.
Napetschnig, J., Kassube, S.A., Debler, E.W., Wong, R.W., Blobel, G., and Hoelz, A. (2009). Structural and functional analysis of the interaction between the nucleoporin Nup214 and the DEAD-box helicase Ddx19. Proc. Natl. Acad. Sci. USA 106, 3089-3094.

Nicol, S.M. and Fuller-Pace, F.V. (1995). The DEAD box protein $\mathrm{DbpA}$ interacts specifically with the peptidyltransferase center in $23 S$ rRNA. Proc. Natl. Acad. Sci. USA 92, $11681-$ 11685.

Nielsen, K.H., Chamieh, H., Andersen, C.B., Fredslund, F., Hamborg, K., Le Hir, H., and Andersen, G.R. (2008). Mechanism of ATP turnover inhibition in the EJC. RNA 15, 67-75.

Oberer, M., Marintchev, A., and Wagner, G. (2005). Structural basis for the enhancement of elF4A helicase activity by elF4G. Genes Dev. 19, 2212-2223.

Ohnishi, S., Paakkonen, K., Koshiba, S., Tochio, N., Sato, M., Kobayashi, N., Harada, T., Watanabe, S., Muto, Y., Guntert, P., et al. (2008). Solution structure of the GUCT domain from human RNA helicase II/Gub reveals the RRM fold, but implausible RNA interactions. Proteins 74, 133-144.

Pause, A. and Sonenberg, N. (1992). Mutational analysis of a DEAD box RNA helicase: the mammalian translation initiation factor elF-4A. EMBO J. 11, 2643-2654.

Pause, A., Methot, N., and Sonenberg, N. (1993). The HRIGRXXR region of the DEAD box RNA helicase eukaryotic translation initiation factor $4 \mathrm{~A}$ is required for RNA binding and ATP hydrolysis. Mol. Cell. Biol. 13, 6789-6798.

Peck, M.L. and Herschlag, D. (1999). Effects of oligonucleotide length and atomic composition on stimulation of the ATPase activity of translation initiation factor elF4A. RNA 5, 12101221.

Peck, M.L. and Herschlag, D. (2003). Adenosine 5'-O-(3thio)triphosphate (ATPgS) is a substrate for the nucleotide hydrolysis and RNA unwinding activities of eukaryotic translation initiation factor elF4A. RNA 9, 1180-1187.

Polach, K.J. and Uhlenbeck, O.C. (2002). Cooperative binding of ATP and RNA substrates to the DEAD/H protein DbpA. Biochemistry 41, 3693-3702.

Pyle, A.M. (2008). Translocation and unwinding mechanisms of RNA and DNA helicases. Annu. Rev. Biophys. 37, 317-336.

Rajkowitsch, L., Chen, D., Stampfl, S., Semrad, K., Waldsich, C., Mayer, O., Jantsch, M.F., Konrat, R., Blasi, U., and Schroeder, R. (2007). RNA chaperones, RNA annealers and RNA helicases. RNA Biol. 4, 118-130.

Rodriguez, A.C. (2002). Studies of a positive supercoiling machine. Nucleotide hydrolysis and a multifunctional latch in the mechanism of reverse gyrase. J. Biol. Chem. 277, 29865-29873.

Rodriguez, A.C. (2003). Investigating the role of the latch in the positive supercoiling mechanism of reverse gyrase. Biochemistry 42, 5993-6004.

Rodriguez, A.C. and Stock, D. (2002). Crystal structure of reverse gyrase: insights into the positive supercoiling of DNA. EMBO J. 21, 418-426.

Rogers, G.W. Jr., Richter, N.J., and Merrick, W.C. (1999). Biochemical and kinetic characterization of the RNA helicase activity of eukaryotic initiation factor 4A. J. Biol. Chem. 274, 12236-12244.

Rogers, G.W. Jr., Lima, W.F., and Merrick, W.C. (2001a). Further characterization of the helicase activity of elF4A. Substrate specificity. J. Biol. Chem. 276, 12598-12608.

Rogers, G.W. Jr., Richter, N.J., Lima, W.F., and Merrick, W.C. (2001b). Modulation of the helicase activity of elF4A by elF4B, elF4H, and elF4F. J. Biol. Chem. 276, 30914-30922.

Rogers, G.W. Jr., Komar, A.A., and Merrick, W.C. (2002). elF4A: the godfather of the DEAD box helicases. Prog. Nucleic Acid Res. Mol. Biol. 72, 307-331.

Rozen, F., Pelletier, J., Trachsel, H., and Sonenberg, N. (1989). A lysine substitution in the ATP-binding site of eucaryotic initiation factor 4A abrogates nucleotide-binding activity. Mol. Cell. Biol. 9, 4061-4063. 
Rozovsky, N., Butterworth, A.C., and Moore, M.J. (2008). Interactions between elF4Al and its accessory factors elF4B and elF4H. RNA 14, 2136-2148.

Rudolph, M.G., Heissmann, R., Wittmann, J.G., and Klostermeier, D. (2006). Crystal structure and nucleotide binding of the Thermus thermophilus RNA helicase Hera N-terminal domain. J. Mol. Biol. 361, 731-743.

Rudolph, M.G. and Klostermeier, D. (2009). The Thermus thermophilus DEAD box helicase Hera contains a modified RNA recognition motif loosely connected to the helicase core. RNA. Doi: 10.1261/rna.1820009.

Rudolph, M.G., Wittmann, J.G., and Klostermeier, D. (2009). Crystallization and preliminary characterization of the Thermus thermophilus RNA helicase Hera C-terminal domain. Acta Crystallogr. Sect. F 65, 248-252.

Saraste, M., Sibbald, P.R., and Wittinghofer, A. (1990). The Ploop - a common motif in ATP- and GTP-binding proteins. Trends Biochem. Sci. 15, 430-434.

Schmid, S.R. and Linder, P. (1992). D-E-A-D protein family of putative RNA helicases. Mol. Microbiol. 6, 283-291.

Schutz, P., Bumann, M., Oberholzer, A.E., Bieniossek, C., Trachsel, H., Altmann, M., and Baumann, U. (2008). Crystal structure of the yeast elF4A-elF4G complex: an RNA-helicase controlled by protein-protein interactions. Proc. Natl. Acad. Sci. USA 105, 9564-9569.

Sengoku, T., Nureki, O., Nakamura, A., Kobayashi, S., and Yokoyama, S. (2006). Structural basis for RNA unwinding by the DEAD-box protein Drosophila Vasa. Cell 125, 287-300.

Singleton, M.R., Dillingham, M.S., and Wigley, D.B. (2007). Structures and mechanism of helicases and nucleic acid translocases. Annu. Rev. Biochem. 76, 23-50.

Story, R.M., Li, H., and Abelson, J.N. (2001). Crystal structure of a DEAD box protein from the hyperthermophile Methanococcus jannaschii. Proc. Natl. Acad. Sci. USA 98, 1465-1470.

Szczelkun, M.D. (2000). How do proteins move along DNA? Lessons from type-I and type-III restriction endonucleases. Essays Biochem. 35, 131-143.

Talavera, M.A. and De La Cruz, E.M. (2005). Equilibrium and kinetic analysis of nucleotide binding to the DEAD-box RNA helicase DbpA. Biochemistry 44, 959-970.

Talavera, M.A., Matthews, E.E., Eliason, W.K., Sagi, I., Wang, J., Henn, A., and De La Cruz, E.M. (2006). Hydrodynamic characterization of the DEAD-box RNA helicase DbpA. J. Mol. Biol. 355, 697-707.

Tanner, N.K. (2003). The newly identified Q motif of DEAD box helicases is involved in adenine recognition. Cell Cycle 2, $18-19$.
Tanner, N.K., Cordin, O., Banroques, J., Doere, M., and Linder, P. (2003). The Q motif: a newly identified motif in DEAD box helicases may regulate ATP binding and hydrolysis. Mol. Cell 11, 127-138.

Theissen, B., Karow, A.R., Kohler, J., Gubaev, A., and Klostermeier, D. (2008). Cooperative binding of ATP and RNA induces a closed conformation in a DEAD box RNA helicase. Proc. Natl. Acad. Sci. USA 105, 548-553.

Tijerina, P., Bhaskaran, H., and Russell, R. (2006). Nonspecific binding to structured RNA and preferential unwinding of an exposed helix by the CYT-19 protein, a DEAD-box RNA chaperone. Proc. Natl. Acad. Sci. USA 103, 16698-16703.

Tsu, C.A. and Uhlenbeck, O.C. (1998). Kinetic analysis of the RNA-dependent adenosinetriphosphatase activity of DbpA, an Escherichia coli DEAD protein specific for $23 \mathrm{~S}$ ribosomal RNA. Biochemistry 37, 16989-16996.

Tsu, C.A., Kossen, K., and Uhlenbeck, O.C. (2001). The Escherichia coli DEAD protein DbpA recognizes a small RNA hairpin in 23 S rRNA. RNA 7, 702-709.

UniProt-Consortium (2008). The universal protein resource (UniProt). Nucleic Acids Res. 36, D190-D195.

von Moeller, H., Basquin, C., and Conti, E. (2009). The mRNA export protein DBP5 binds RNA and the cytoplasmic nucleoporin NUP214 in a mutually exclusive manner. Nat. Struct. Mol. Biol. 16, 247-254.

Walker, J.E., Saraste, M., Runswick, M.J., and Gay, N.J. (1982). Distantly related sequences in the a- and b-subunits of ATP synthase, myosin, kinases and other ATP-requiring enzymes and a common nucleotide binding fold. EMBO J. 1, 945-951.

Wang, S., Hu, Y., Overgaard, M.T., Karginov, F.V., Uhlenbeck, O.C., and McKay, D.B. (2006). The domain of the Bacillus subtilis DEAD-box helicase YxiN that is responsible for specific binding of $23 \mathrm{~S}$ rRNA has an RNA recognition motif fold. RNA 12, 959-967.

Wang, S., Overgaard, M.T., Hu, Y., and McKay, D.B. (2007). The Bacillus subtilis RNA helicase YxiN is distended in solution. Biophys. J. 94, L01-L03.

Yang, Q. and Jankowsky, E. (2005). ATP- and ADP-dependent modulation of RNA unwinding and strand annealing activities by the DEAD-box protein DED1. Biochemistry 44, 1359113601.

Yang, Q. and Jankowsky, E. (2006). The DEAD-box protein Ded1 unwinds RNA duplexes by a mode distinct from translocating helicases. Nat. Struct. Mol. Biol. 13, 981-986.

Received June 4, 2009; accepted July 31, 2009 